Research Article

\title{
Understanding Pore Surface Modification of Sucrose- Modified Iron Oxide/Silica Mesoporous Composite for Degradation of Methylene Blue
}

\author{
Yuvita Eka Pertiwi ${ }^{1}$, Maria Ulfa ${ }^{2, *}$, Teguh Endah Saraswati ${ }^{1}$, Didik Prasetyoko $^{3}$, \\ Wega Trisunaryanti ${ }^{4}$
}

\author{
${ }^{1}$ Department of Chemistry, Faculty of Mathematics and Natural Sciences, Sebelas Maret University, \\ Jl. Ir. Sutami 36A Surakarta 57126 Indonesia. \\ ${ }_{2}^{2}$ Department of Chemistry Education, Faculty of Teacher Training and Education, Sebelas Maret University, \\ Jl. Ir. Sutami 36A Surakarta 57126 Indonesia. \\ ${ }^{3}$ Department of Chemistry, Faculty of Science and Data Analytics, Institut Teknologi Sepuluh Nopember, \\ Keputih, Sukolilo, Surabaya 60111, Indonesia. \\ ${ }^{4}$ Department of Chemistry, Faculty of Mathematics and Natural Sciences, Gadjah Mada University, \\ Sekip Utara Bulaksumur 21 Yogyakarta 55281 Indonesia.
}

Received: 15 $5^{\text {th }}$ March 2021; Revised: 30th April 2021; Accepted: $5^{\text {th }}$ May 2021

Available online: $10^{\text {th }}$ May 2021; Published regularly: September 2021

\section{Abstract}

Santa Barbara Amorphous (SBA-15) containing iron oxide with a sucrose-modified in a heterogeneous reaction for degradation methylene blue (MB) successful synthesized used hydrothermal, ultrasonication, and wet impregnation method. SBA-15 is mesoporous silica that can easily serve as external and internal surfaces making it suitable for a wide range of applications. The structure and morphology of materials were characterized using Surface Area Analyzer (SAA), X-ray diffraction (XRD), Fourier Transform Infrared Spectroscopy (FTIR), Scanning Electron Microscope-Energy Dispersive X-Ray (SEM-EDX), and Transmission Electron Microscopy (TEM). Iron oxide impregnated as a maghemite phase has an average size of $12 \mathrm{~nm}$ and well distributed on the SBA-15. After modified with sucrose the materials remaining stable, which has a two-dimensional hexagonal (p6mm) structure, high specific surface area, and large pore volume (up to $1.82 \mathrm{~cm}^{3} \cdot \mathrm{g}^{-1}$ ). The degradation of MB was evaluated under visible light irradiation using UV-Vis spectroscopy. Catalytic activity showed efficiencies of 52.9; 70.2 ; and $21.1 \%$ for SBA-15, $\mathrm{Fe}_{2} \mathrm{O}_{3} / \mathrm{SBA}-15$, and sucrose-modified $\mathrm{Fe}_{2} \mathrm{O}_{3} / \mathrm{SBA}-15$ respectively. Sucrose-modified $\mathrm{Fe}_{2} \mathrm{O}_{3} / \mathrm{SBA}-15$ has the lowest efficiency, which probably occurs due to the presence of pore-blocking and the formation of micropores on the external pore. The modification with sucrose has the advantage of producing a high surface area even though there is a catalytic center due to partial decomposition which causes a decrease in the efficiency of degradation of MB. All materials provide a high micro surface area so that they can be further adapted and can be widely applied to many potential applications as both catalyst support and an adsorbent.

Copyright (C) 2021 by Authors, Published by BCREC Group. This is an open access article under the CC BY-SA License (https://creativecommons.org/licenses/by-sa/4.0).

Keywords: Sucrose-modified; iron oxide silica; SBA-15; composite; $\mathrm{Fe}_{2} \mathrm{O}_{3} / \mathrm{SBA}-15$; methylene blue

How to Cite: Y.E. Pertiwi, M. Ulfa, T.E. Saraswati, D. Prasetyoko, W. Trisunaryanti (2021). Understanding Pore Surface Modification of Sucrose-Modified Iron Oxide/Silica Mesoporous Composite for Degradation of Methylene Blue. Bulletin of Chemical Reaction Engineering \& Catalysis, 16(3), 459-471 (doi:10.9767/bcrec.16.3.10619.459471)

Permalink/DOI: https://doi.org/10.9767/bcrec.16.3.10619.459-471

\section{Introduction}

The photocatalytic method is a method used to decompose organic compounds into simpler

\footnotetext{
* Corresponding Author.

Email: ulfa.maria2015@gmail.com (M.Ulfa);
}

compounds using photon energy and UV radiation. Over the last few decades, photocatalyst technology has developed rapidly as a new approach in finding solutions to clean environmental pollutants [1,2]. Various types of functional materials have been synthesized and applied as 
photocatalysts for efficient degradation of methylene blue (MB) under visible radiation [3]. One approach to increasing catalytic activity is through increasing the efficiency of photogeneration carriers (electrons and photogeneration holes) with suitable heterogeneous catalyst support materials (such as precious metals and metal oxides) or building catalysts with various compositions and surfaces structures [4]. Another advantage of heterogeneous catalysts is that they can be reused by simple regeneration methods such as washing and high temperature decomposition. Mesoporous silica type catalytic support materials, such as MCM-41 and SBA-15 have been used as catalyst supports for metal catalyst dispersion [5,6]. Mesoporous silica SBA-15 is one of the molecular filters [7] which is inert, highly regular structure, large pore size (range 4-30 nm), thick frame walls [8], and higher thermal interference than M41S materials [9]. Mesoporous silica synthesis is a simple method that involves forming micellar from a surfactant as a soft template for silica sources followed by hydrothermal and calcination processes (Figure 1).

However, for photocatalyst applications, the structure of porous silica is generally only dominated by silanol $(\mathrm{Si}-\mathrm{OH})$ so that the photocatalyst process only centers on the dispersed catalyst metal on the surface of the silica. The lack of functional groups in the support material will reduce the ability of the chemical and physical interactions of the catalyst material. Chemical interactions in photocatalytic occur through functional groups that easily bind to organic molecules to be catalyzed, while physical interactions occur through contact between pores and organic molecules during absorption. On the other hand, the character of SBA-15 mesoporous silica with its high surface area, biocompatibility, chemical stability, and adjustable porous structure makes the mesoporous silica surface easy to modify [10]. So that the problem of the lack of functional groups in mesoporous silica SBA-15 can be handled by surface modification with organic molecules.

Functionalization methods that have been widely used in previous research are the cocondensation method, the encapsulation process, and post-synthesis techniques, such as the grafting technique. One of the surface modification techniques is the surface functionalization of the catalyst material in general by adding organic or inorganic compounds which have a catalytic process support functional group. Several researchers have modified mesoporous silica through functionalization with modifying agents [11], doping with nitrogen [12,13], and oxidation with acid solutions [14]. On the other hand, it has prepared mesoporous silica-based composites through the loading of iron oxides [15,16], zero valence iron [17], double metal oxides [18] on SBA-15 mesoporous silica. Functionalization in previous studies generally uses metal oxide embedding. Functionalization with organic compounds is very rare in previous research. One of the potential organic compounds as a functionalization agent is sucrose.
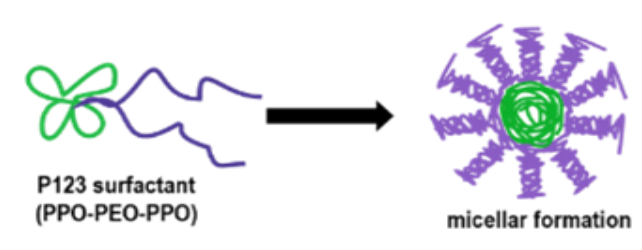
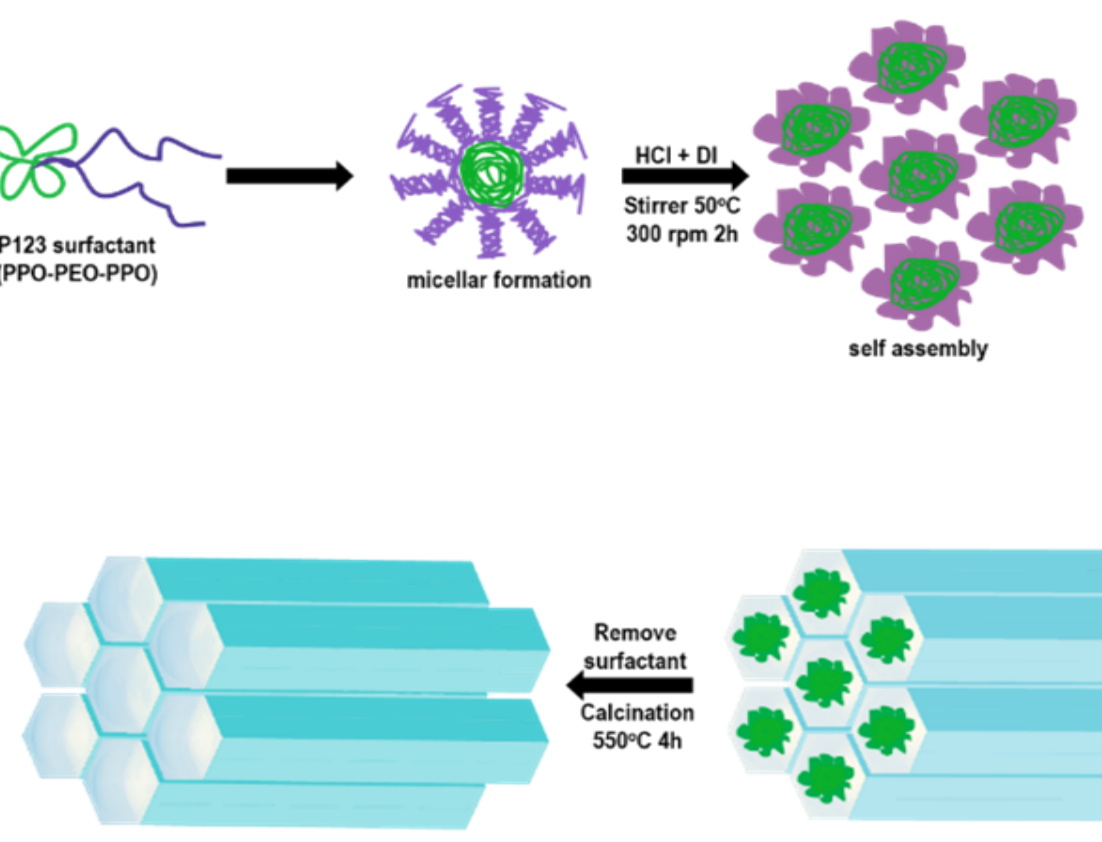

Silica source

TEOS

\section{Stirrer $50^{\circ} \mathrm{C}$}

$300 \mathrm{rpm} 4 \mathrm{~h}$

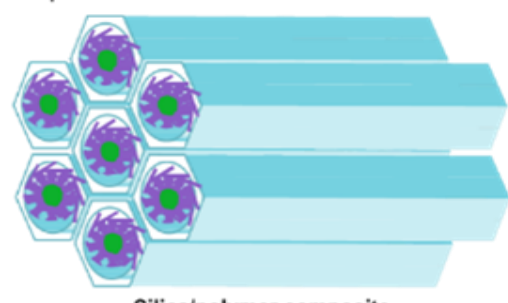

Remove

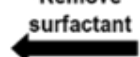

Calcination

$550^{\circ} \mathrm{C} 4 \mathrm{~h}$

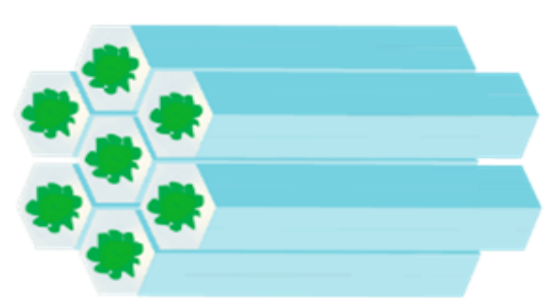

Silica/polymer composite

Hydrothermal Oven $100^{\circ} \mathrm{C} 24 \mathrm{~h}$

Figure 1. A schematic synthesis of silica SBA-15. 
Sucrose is a polymer compound that can be used as supporting material and stabilizes ordinary mesostructures [19]. In addition, sucrose is an organic material that is environmentally friendly and effective for the dispersion of nanoparticles [20]. In general, sucrose, like other oligosaccharides, undergoes hydrolysis in acidic media and forms monosaccharides. In addition, sucrose can undergo further degradation into heterocyclic aldehydes (furfurals) suitable for the addition of the $-\mathrm{OH}$ functional groups or double carbon chains in the functionalization of materials [21]. Surface modification of mesoporous silica through the addition of sucrose can affect the adsorption characteristics of the final material.

The adsorption characteristics of materials are very important considerations in dye degradation applications. However, to the best of our knowledge, research on the modification of silica-based catalyst materials by the sucrose functionalization method has not been carried out before. Based on this, this research will study the effect of adding sucrose to the mesoporous structure of impregnated metal oxide SBA-15 silica to explain the effect of functionalization in the photocatalytic application of methylene blue. Iron oxide impregnated into SBA-15 mesoporous silica is hematite $\left(\alpha-\mathrm{Fe}_{2} \mathrm{O}_{3}\right)$ because it has high photocatalyst performance due to its small band gap (2.1-2.2 eV), which is advantageous for absorbing photons in the visible light range, chemically stable, and cost-effective [22]. The functionalization of sucrose in iron ox-
ide/SBA-15 is expected to increase the attractiveness of the MB molecular group and increase the overall photocatalytic results due to the support of the pore number of SBA-15 and the additional functional groups of sucrose (Figure 2). Material properties were studied with Surface Area Analyzer (SAA), Fourier Transform Infrared Spectroscopy (FTIR), Scanning Electron Microscope-Energy Dispersive XRay (SEM-EDX), Transmission Electron Microscopy (TEM), and catalytic activity was studied through UV-Visible spectroscopy.

\section{Materials and Methods}

\subsection{Materials}

The equipment used in this study includes furnace OTF 1200X, oven (Memmert UF110), UV-Visible spectroscopy (Perkin Elmer Lambda 25), black box reactor, and mercury lamp (Philips HPL-N 125W/542 E27). The research materials used include Pluronic 123 (Merck, $\sim 5800 \mathrm{~g} / \mathrm{mol}$ molar mass), TEOS (tetraethyl orthosilicate, $98.0 \%$ ), $\mathrm{Fe}\left(\mathrm{NO}_{3}\right)_{3} .9 \mathrm{H}_{2} \mathrm{O}$ (Merck, $403.95 \mathrm{~g} / \mathrm{mol}$ molar mass), sucrose (SigmaAldrich, $342.3 \mathrm{~g} / \mathrm{mol}$ molar mass), and $\mathrm{HCl}$ solution (Merck, 37\%).

\subsection{Synthesis of Santa Barbara Amorphous (SBA-15) with Hydrothermal Method}

SBA-15 was synthesized by hydrothermal method according to research conducted by Zhao et al. [23] modified by Belmoujahid et al.

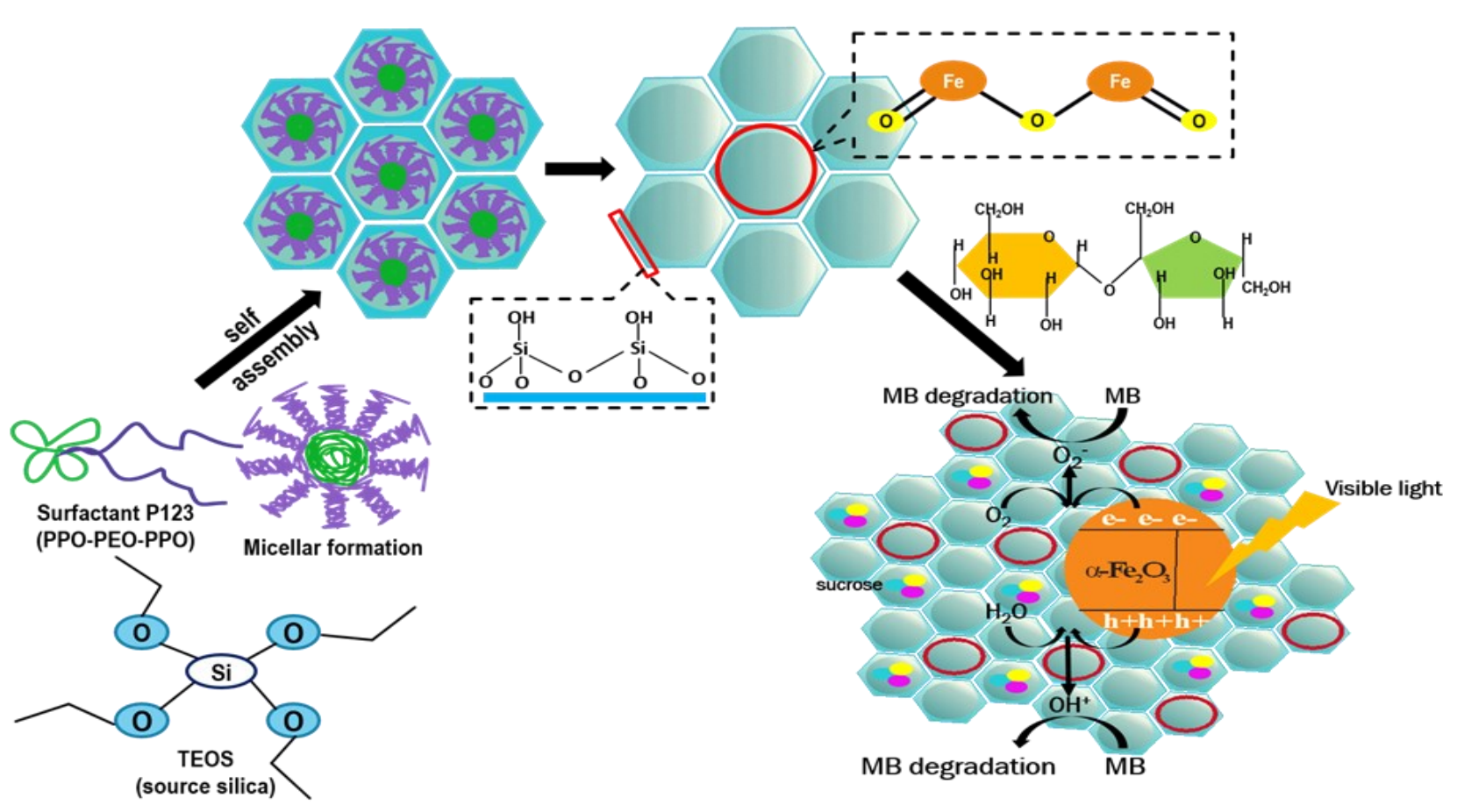

Figure 2. A schematic showing the sucrose-modified iron oxide/silica mesoporous SBA-15. 
[24]. First, $4 \mathrm{~g}$ of P123 were dissolved in an acid medium with $19.5 \mathrm{~mL}$ of concentrated hydrochloric acid (37\%) and $127 \mathrm{~mL}$ of distilled water. The mixture was stirred with a magnetic stirrer so that it was homogeneous at $300 \mathrm{rpm}$ for 2 hours at $50^{\circ} \mathrm{C}$. After that, the $8.62 \mathrm{~g}$ TEOS (silica source) was added to a homogeneous mixture with a ratio of 1 TEOS: 0.017 P123: $5.68 \mathrm{HCl}: 197 \mathrm{H}_{2} \mathrm{O}$ and continued stirred with a magnetic stirrer under the same conditions for 4 hours. The mixture was put into an autoclave and heated in an oven for aging processes for 24 hours at $100{ }^{\circ} \mathrm{C}$. The white precipitate obtained was filtered using a Buchner funnel and washed with $200 \mathrm{~mL}$ distilled water.

Furthermore, the material was dried using an oven for 24 hours at a temperature of 100 ${ }^{\circ} \mathrm{C}$. If there were still small grains, they must be crushed to produce a very fine powder. The P123 surfactant was removed to produce pores through calcined at $550{ }^{\circ} \mathrm{C}$ for 4 hours, then cooled to room temperature.

\subsection{Synthesis Sucrose-modified $\mathrm{Fe}_{2} \mathrm{O}_{3} / \mathrm{SBA}-15$}

$\mathrm{Fe}_{2} \mathrm{O}_{3} / \mathrm{SBA}-15$ was prepared using $\mathrm{Fe}\left(\mathrm{NO}_{3}\right)_{3} .9 \mathrm{H}_{2} \mathrm{O}$ as a metal precursor which was studied by wet impregnation by dissolving $\mathrm{Fe}\left(\mathrm{NO}_{3}\right)_{3} .9 \mathrm{H}_{2} \mathrm{O}$ into distilled water then added SBA-15 powder. The mixture was ultrasonicated for 15 minutes then stirred with a magnetic

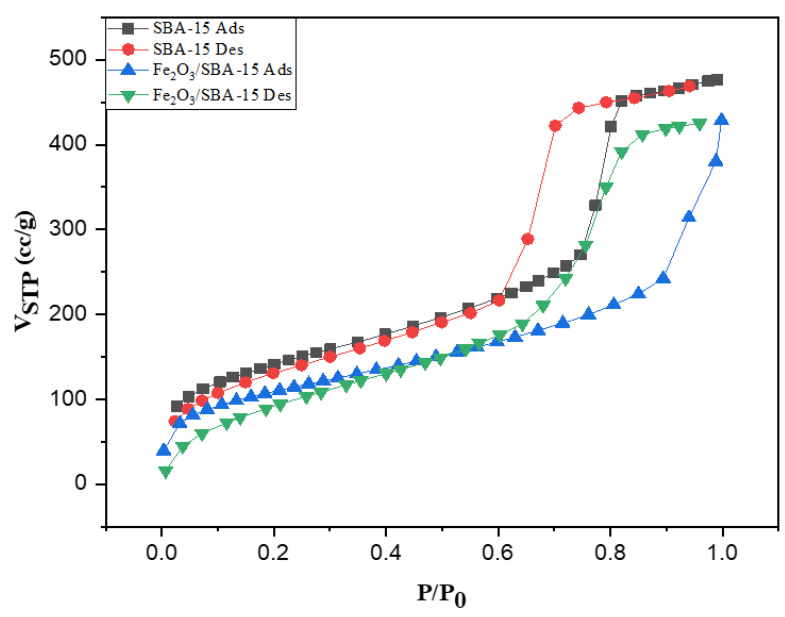

Figure $3 . \mathrm{N}_{2}$ adsorption-desorption isotherm for synthesized SBA-15 and $\mathrm{Fe}_{2} \mathrm{O}_{3} / \mathrm{SBA}-15$. stirrer at a temperature of $50{ }^{\circ} \mathrm{C}$ at $300 \mathrm{rpm}$ for 4 hours. Furthermore, the material was dried using an oven at $100{ }^{\circ} \mathrm{C}$ for 24 hours. The material was calcined at $750{ }^{\circ} \mathrm{C}$ for 4 hours to obtain $\mathrm{Fe}_{2} \mathrm{O}_{3} /$ SBA-15.

A sucrose solution was prepared with $1.25 \mathrm{~g}$ of sucrose dissolved in $5.0 \mathrm{~mL}$ of distilled water and $0.076 \mathrm{~mL}$ of $\mathrm{H}_{2} \mathrm{SO}_{4}$ added dropwise, while stirring. Furthermore, $\mathrm{Fe}_{2} \mathrm{O}_{3} / \mathrm{SBA}-15$ was added to the sucrose solution. The resulting mixture was put in an oven for 6 hours at 100 ${ }^{\circ} \mathrm{C}$, and continued at $160{ }^{\circ} \mathrm{C}$ for 6 hours. The second solution was prepared with $0.85 \mathrm{~g}$ of sucrose dissolved in $0.049 \mathrm{~mL} \mathrm{H} \mathrm{HO}_{4}$ and $5.0 \mathrm{~mL}$ distilled water. A silica sample containing partially polymerized sucrose was added from the previous step. Then, the two-step heating procedure was repeated to dry the resulting mixture. Finally, dark brown powders were characterized by SAA, FTIR, SEM-EDX, and TEM.

The photocatalytic degradation activity of MB was carried out under visible light radiation. The visible light source used was a $125 \mathrm{~W}$ mercury lamp. The mass ratio of iron oxide/SBA-15 modified with sucrose and MB was 1:5 with a concentration of $5 \mathrm{ppm}$. Then the mixture was stirred using a shaker $(250 \mathrm{rpm})$ in a black box reactor and given a mercury lamp. The absorbance measurement used UVVis spectroscopy at a wavelength of $663 \mathrm{~nm}$ with time variations of $0,15,30,45$, and 60 minutes.

\section{Results and Discussion}

The specific surface area and pore structure of SBA-15, $\mathrm{Fe}_{2} \mathrm{O}_{3} / \mathrm{SBA}-15$, and sucrose-modified $\mathrm{Fe}_{2} \mathrm{O}_{3} /$ SBA- 15 were characterized by BrunauerEmmett-Teller (BET) method and the nitrogen sorption isotherms and Barrett-JoynerHalenda (BJH) pore size distribution curve. For comparison, the results of BET specific surface area and pore structure information are summarized in Table 1.

According to the classification of the International Union of Pure and Applied Chemistry (IUPAC), two isotherm curves in Figure 3 indicate the presence of $\mathrm{N}_{2}$ uptake as a result of capillary condensation and can be classified as IV

Table 1. The surface area analysis results of SBA-15, $\mathrm{Fe}_{2} \mathrm{O}_{3} / \mathrm{SBA}-15$, and sucrose-modified $\mathrm{Fe}_{2} \mathrm{O}_{3} / \mathrm{SBA}-15$.

\begin{tabular}{lcccc}
\hline Sample & $S_{\text {BET }}\left(\mathrm{m}^{2} \cdot \mathrm{g}^{-1}\right)$ & $S_{\text {ВJн }}\left(\mathrm{m}^{2} \cdot \mathrm{g}^{-1}\right)$ & $V_{\text {ВJн }}\left(\mathrm{cm}^{3} \cdot \mathrm{g}^{-1}\right)$ & $D_{\text {ВJн }}(\mathrm{nm})$ \\
\hline SBA-15 & 498.9 & 292.8 & 0.73 & 10 \\
$\mathrm{Fe}_{2} \mathrm{O}_{3} / \mathrm{SBA}-15$ & 389.5 & 160.2 & 0.66 & 3.2 \\
Sucrose-modified $\mathrm{Fe}_{2} \mathrm{O}_{3} / \mathrm{SBA}-15$ & 1980 & 25370 & 1.82 & 3.2 \\
\hline
\end{tabular}


type isotherm for mesoporous type which gives relative BET surface area (498.9 and 389.5 $\mathrm{m}^{2} \cdot \mathrm{g}^{-1}$, respectively, Table 1$)$. Meanwhile, the results of the sucrose modification of $\mathrm{Fe}_{2} \mathrm{O}_{3} / \mathrm{SBA}-15$ showed the BET and BJH surface area, 1980 and $25370 \mathrm{~m}^{2} \cdot \mathrm{g}^{-1}$, respectively.

Furthermore, it can be seen from Figure 3 that the $\mathrm{H} 1$ type hysteresis is formed with narrow slit holes in a wide relative pressure $\mathrm{P} / \mathrm{P}_{0}$ range 0.6 to 0.8 for mesoporous $\mathrm{SBA}-15$. It suggests SBA-15 is a cylindrical material and exists mesopore structure and the compounds have uniform mesoporous structures and slit pore geometry [15].

The $\mathrm{Fe}_{2} \mathrm{O}_{3} / \mathrm{SBA}-15$ exhibits hysteresis of H2(b) type associated with pore-blocking by iron oxide particles on mesoporous SBA-15 [25]. In Table 1 also shows that in the pore volume of SBA-15, $\mathrm{Fe}_{2} \mathrm{O}_{3} / \mathrm{SBA}-15$, and sucrose-modified $\mathrm{Fe}_{2} \mathrm{O}_{3} / \mathrm{SBA}-15$ are $0.73,0.66$, and $1.82 \mathrm{~cm}^{3} \cdot \mathrm{g}^{-1}$. A reduction in specific surface area, total pore volume, and mesopore size are observed, as expected for a successful impregnation of iron oxide on mesoporous SBA-15. Meanwhile, the increase in surface area and total pore volume in sucrose-modified $\mathrm{Fe}_{2} \mathrm{O}_{3} / \mathrm{SBA}-15$ is predicted to
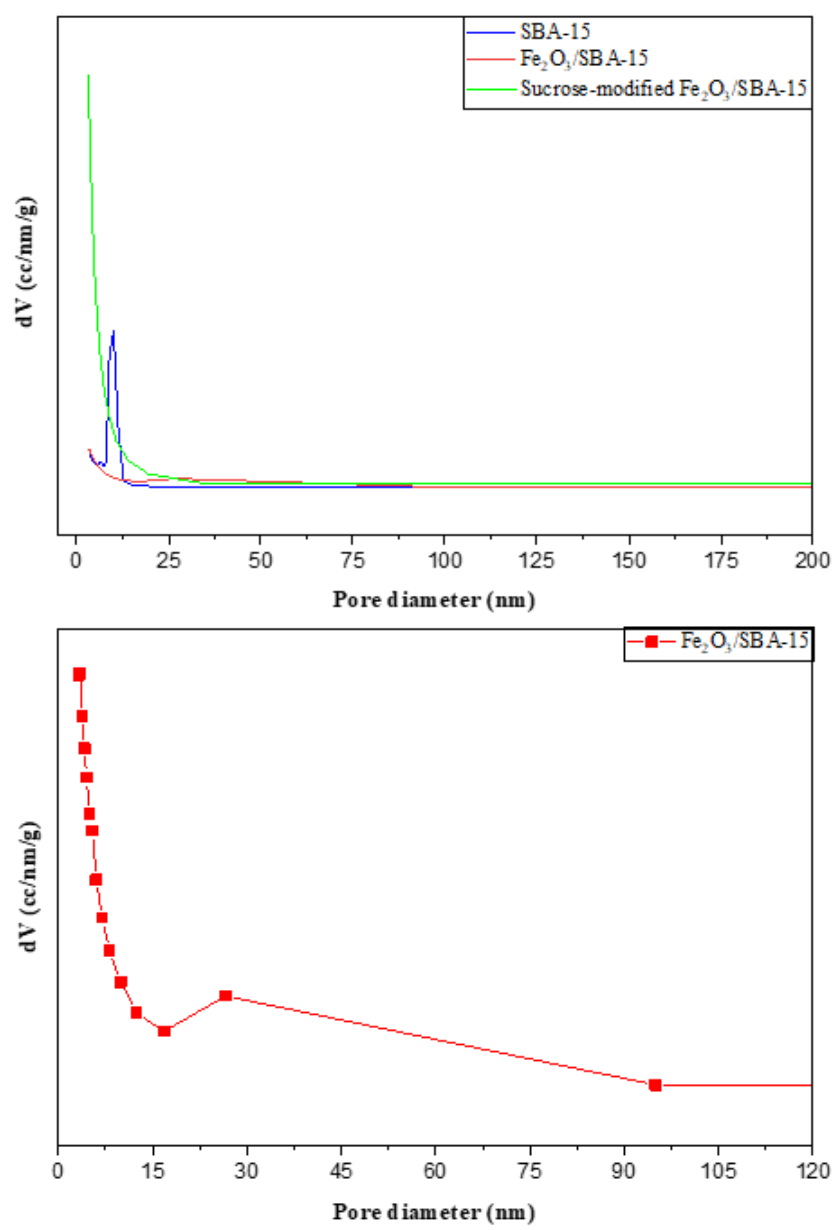

come from the formation of micropores from the conversion of sucrose to carbon, where some of the carbon from sucrose fills the micropores and mesopore. This will cause the formation of becomes micropore carbon and mesoporous carbon after heating $100-160{ }^{\circ} \mathrm{C}$ with the help of an acid catalyst. This is confirmed by the elemental analysis, where $30.9 \%$ carbon was detected in the sample and contributed pores to the sucrose-modified $\mathrm{Fe}_{2} \mathrm{O}_{3} / \mathrm{SBA}-15$.

The pore size distributions of SBA-15, $\mathrm{Fe}_{2} \mathrm{O}_{3} / \mathrm{SBA}-15$, and sucrose-modified $\mathrm{Fe}_{2} \mathrm{O}_{3} / \mathrm{SBA}-15$ shown in Figure 4 were obtained from the desorption analysis of the branches in the isotherm. It can be seen that the three materials have a pore size distribution of SBA-15 which is loaded at $10 \mathrm{~nm}$, the $\mathrm{Fe}_{2} \mathrm{O}_{3} / \mathrm{SBA}-15$ have a bimodal pore size distribution centered at 3.2 and $10 \mathrm{~nm}$, while sucrose modified shows the dominance of micropores where the majority pore distribution is at the pore size below 5 nm. This was confirmed by XRD and SEMEDX, where the SBA-15 material had the dominant mesopores of the P123, TEOS selfassembly processes as a surfactant and source of silica. Meanwhile, after impregnation with
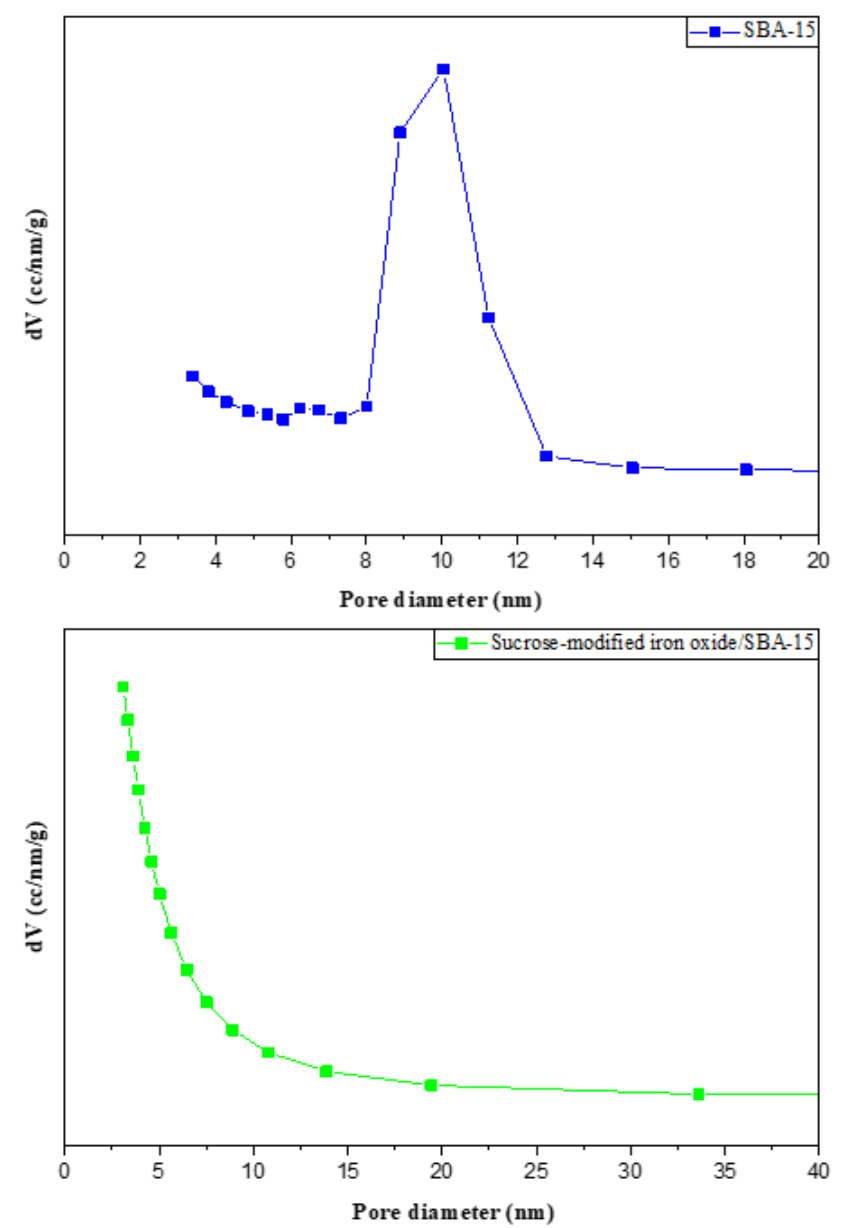

Figure 4. Pore size distribution of SBA-15; $\mathrm{Fe}_{2} \mathrm{O}_{3} / \mathrm{SBA}-15$; and sucrose-modified $\mathrm{Fe}_{2} \mathrm{O}_{3} / \mathrm{SBA}_{-15}$ 
the $\mathrm{Fe}_{2} \mathrm{O}_{3}$ source, the sample was transformed into a bimodal pore due to iron oxide blocking of SBA-15 pores. Interestingly, the modification with sucrose in a micropore dominant pore size distribution because the mesoporous part of the SBA-15 pore was not only covered by micropore carbon from partially carbonized sucrose but was also covered by $\mathrm{Fe}_{2} \mathrm{O}_{3}$ when pore filling of the silica wall during the modification period.

The composition information and chemical bonding structure of SBA-15, $\mathrm{Fe}_{2} \mathrm{O}_{3} / \mathrm{SBA}-15$, and sucrose-modified $\mathrm{Fe}_{2} \mathrm{O}_{3} / \mathrm{SBA}-15$ were identified used FTIR spectroscopy as shown in Figure 5. Results of the IR spectra shows the same adsorption peaks at around $460 \mathrm{~cm}^{-1}$ assigned to the $\mathrm{Si}-\mathrm{O}$ bending stretching vibration [26]. The adsorption peaks at around $1065 \mathrm{~cm}^{-1}$ and $810 \mathrm{~cm}^{-1}$ are attributed to the asymmetric and symmetric stretching vibration mode of $\mathrm{Si}-\mathrm{O}-\mathrm{Si}$, respectively $[27,28]$.

The peaks around at $3400 \mathrm{~cm}^{-1}$ and 1623 $\mathrm{cm}^{-1}$ are belong to the stretching vibration of $\mathrm{O}-\mathrm{H}$ associated with physisorption water and surface silanol groups of SBA-15 [29]. In addition, it is shown also peak at around 590, 568, and $540 \mathrm{~cm}^{-1}$ detected in the iron oxide impregnated silica mesopore correspond to the stretching vibration of $\mathrm{Fe}-\mathrm{O}$. Based on the results indicates that iron oxide has been successfully dispersed on the SBA-15 silica mesoporous material. The peak around at $1722 \mathrm{~cm}^{-1}$ was attributed to carbonyl stretching [30]. The peaks at $2929 \mathrm{~cm}^{-1}, 1410 \mathrm{~cm}^{-1}$, and $1201 \mathrm{~cm}^{-1}$ assigned to the stretching $\mathrm{C}-\mathrm{H}$, bending $\mathrm{CH}_{2}$, and $\mathrm{C}-\mathrm{O}$, respectively show that the functionalized surface of sucrose-modified
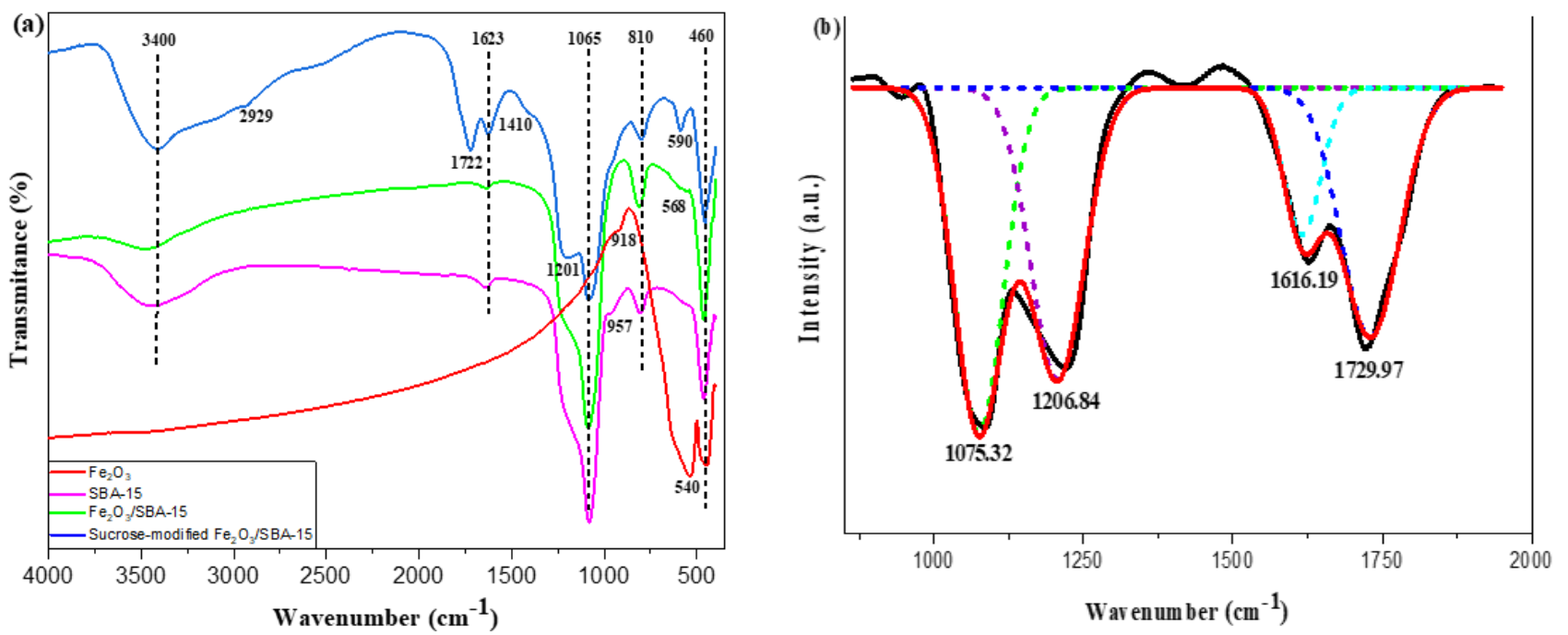

Figure 5. Spectra IR of SBA-15; $\mathrm{Fe}_{2} \mathrm{O}_{3} / \mathrm{SBA}-15$; and sucrose-modified $\mathrm{Fe}_{2} \mathrm{O}_{3} / \mathrm{SBA}-15$ (a), and representative deconvolution IR of sucrose-modified $\mathrm{Fe}_{2} \mathrm{O}_{3} / \mathrm{SBA}-15(\mathrm{~b})$.
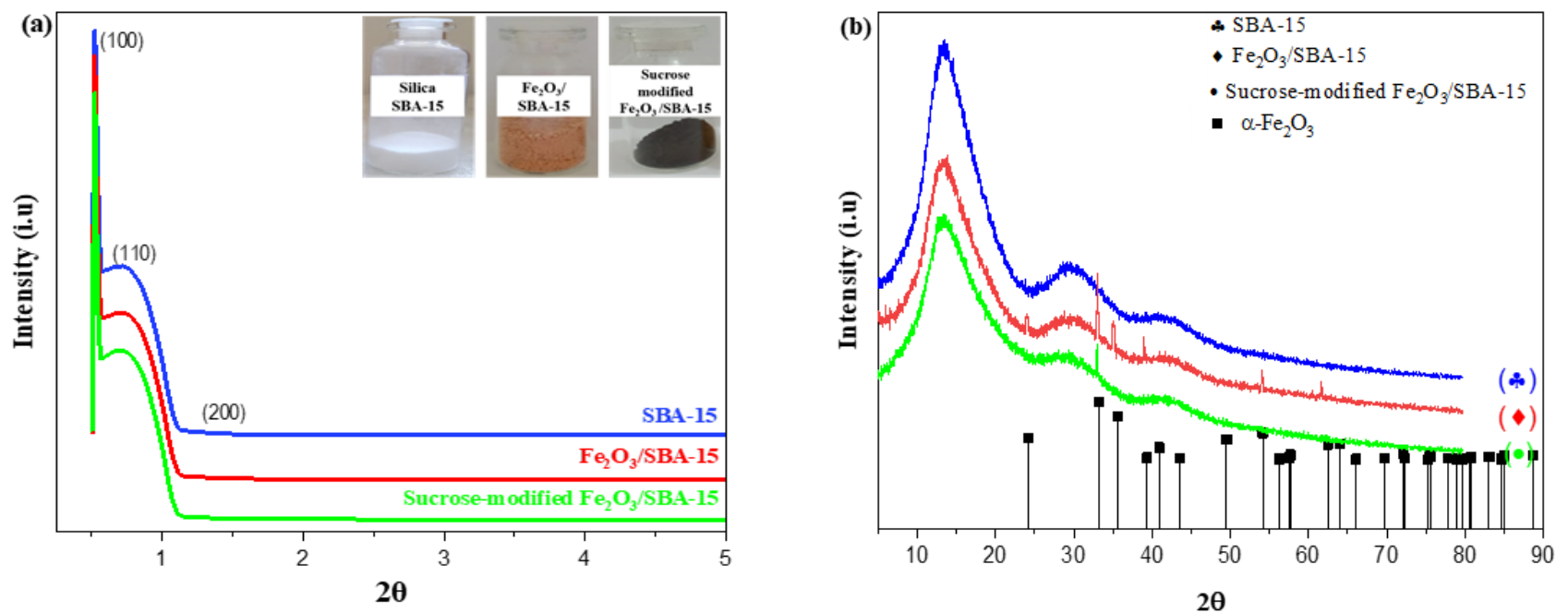

Figure 6. Low-angle (a) and wide-angle (b) XRD patterns for hematite, SBA-15, $\mathrm{Fe}_{2} \mathrm{O}_{3} / \mathrm{SBA}-15$ and sucrose-modified $\mathrm{Fe}_{2} \mathrm{O}_{3} / \mathrm{SBA}-15$. 
$\mathrm{Fe}_{2} \mathrm{O}_{3} / \mathrm{SBA}-15$ [31]. By deconvolving the sucrose-modified $\mathrm{Fe}_{2} \mathrm{O}_{3} / \mathrm{SBA}-15$ in the Gaussian profile showed the fourfold are $\mathrm{Si}-\mathrm{O}-\mathrm{Si}$ $\left(1075.32 \mathrm{~cm}^{-1}\right), \mathrm{CH}_{2}\left(1206.84 \mathrm{~cm}^{-1}\right), \mathrm{C}=\mathrm{C}$ asymmetric $\left(1616.19 \mathrm{~cm}^{-1}\right)$, and $\mathrm{C}=\mathrm{O}\left(1729.97 \mathrm{~cm}^{-1}\right)$. Illustrates of deconvolution the appearance of three peaks in the $1200-1800 \mathrm{~cm}^{-1}$ range confirm that the sucrose modification of iron oxide/SBA-15 was successful [32].

XRD patterns of SBA-15, $\mathrm{Fe}_{2} \mathrm{O}_{3} / \mathrm{SBA}-15$ and sucrose-modified $\mathrm{Fe}_{2} \mathrm{O}_{3} / \mathrm{SBA}-15$ in wide-angle, and low-angle are shown in Figure 6. All of
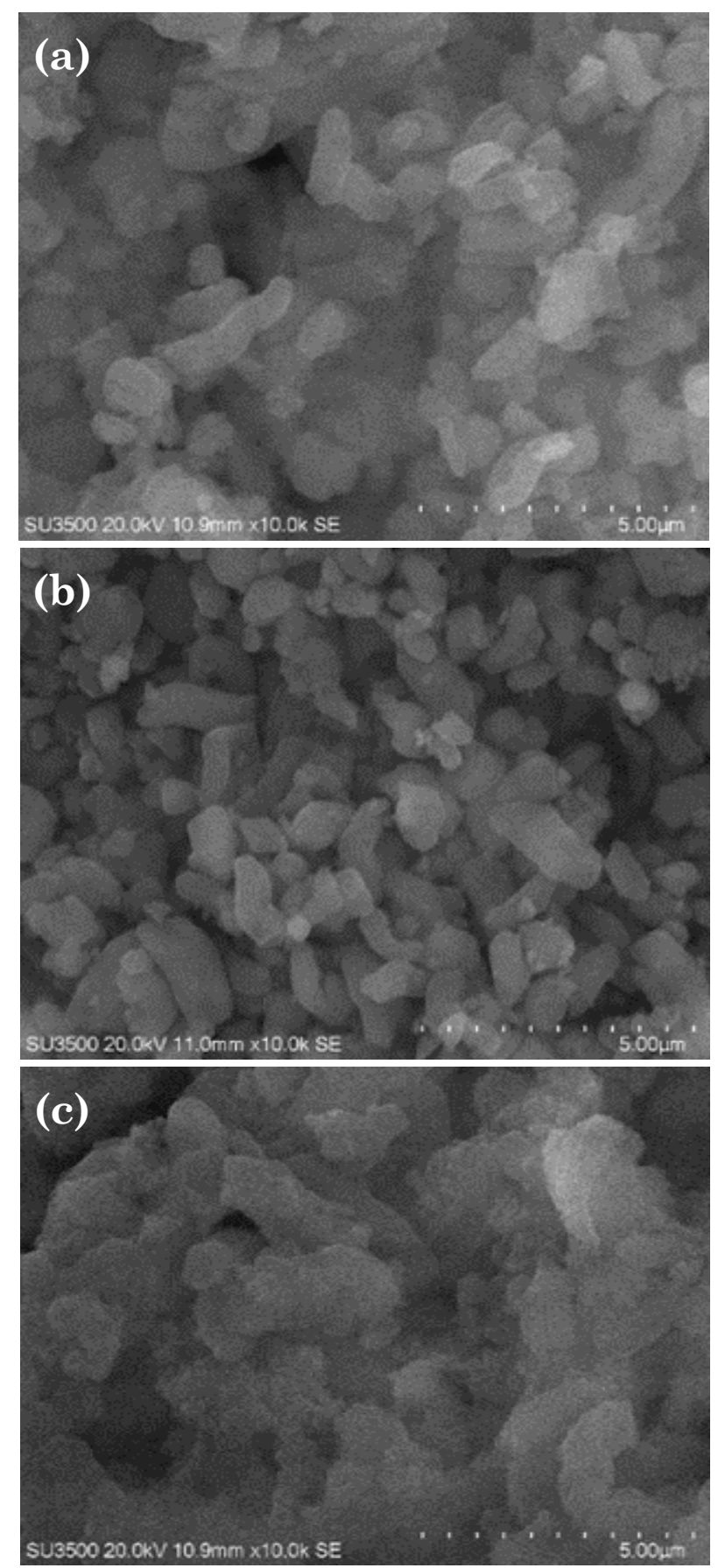

samples show three identical (100), (110), and (200) reflections of the $2 \mathrm{D}$ hexagonal mesostructure with p6mm symmetry in low-angle XRD pattern (Figure 6 (a)), which suggests the ordered hexagonal mesoporous structure of SBA-15 is kept after different treatment $[33,34]$. The wide angle XRD patterns are shown in Figure 6 (b), a broad peak appeared in the $2 \theta$ range $15^{\circ}$ is attributed to the basic structure of SBA-15. It does not vanish even after loading iron oxide species into the silica mesopore SBA-15.
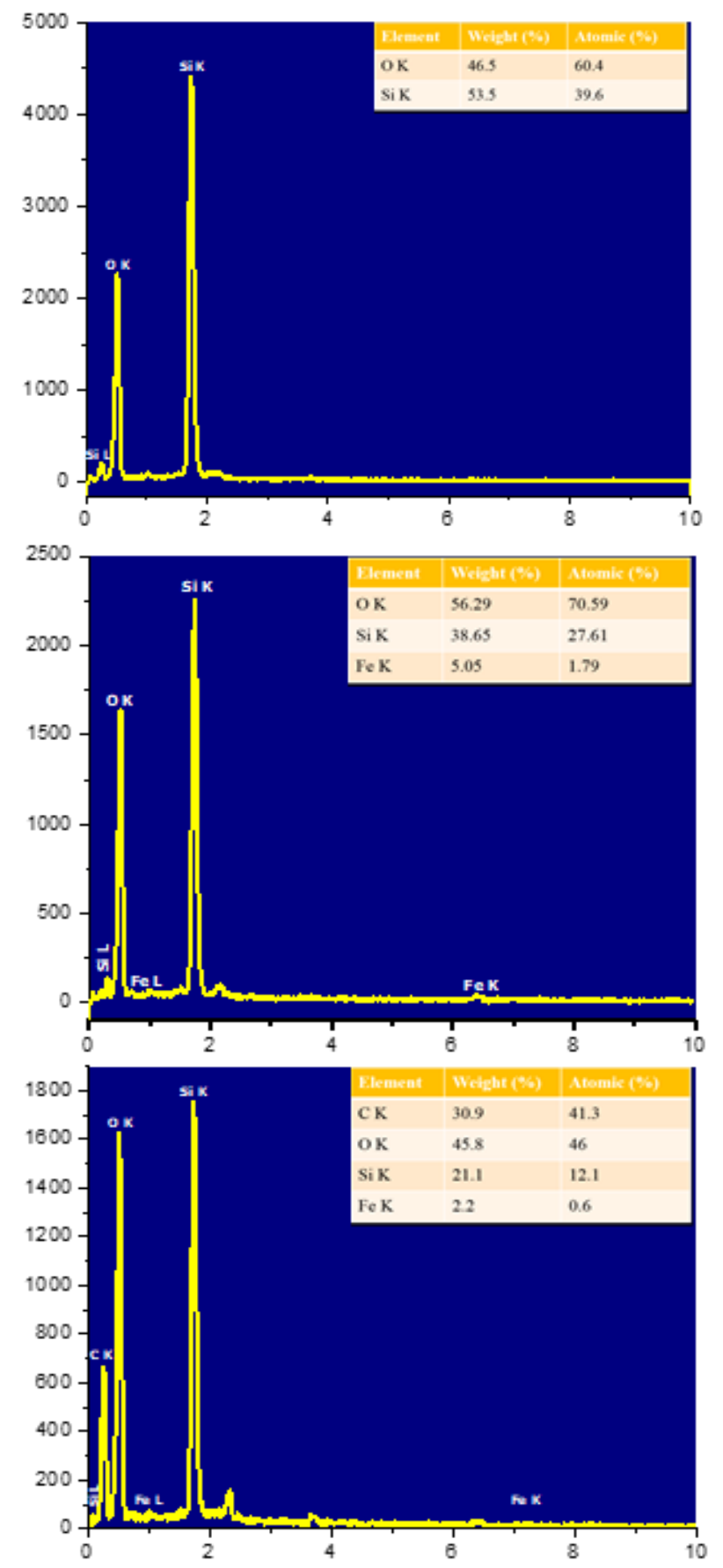

Figure 7. SEM with EDX images of a) SBA-15; b) $\mathrm{Fe}_{2} \mathrm{O}_{3} / \mathrm{SBA}-15$ and c) sucrose-modified $\mathrm{Fe}_{2} \mathrm{O}_{3} / \mathrm{SBA}^{-}$ 15. 


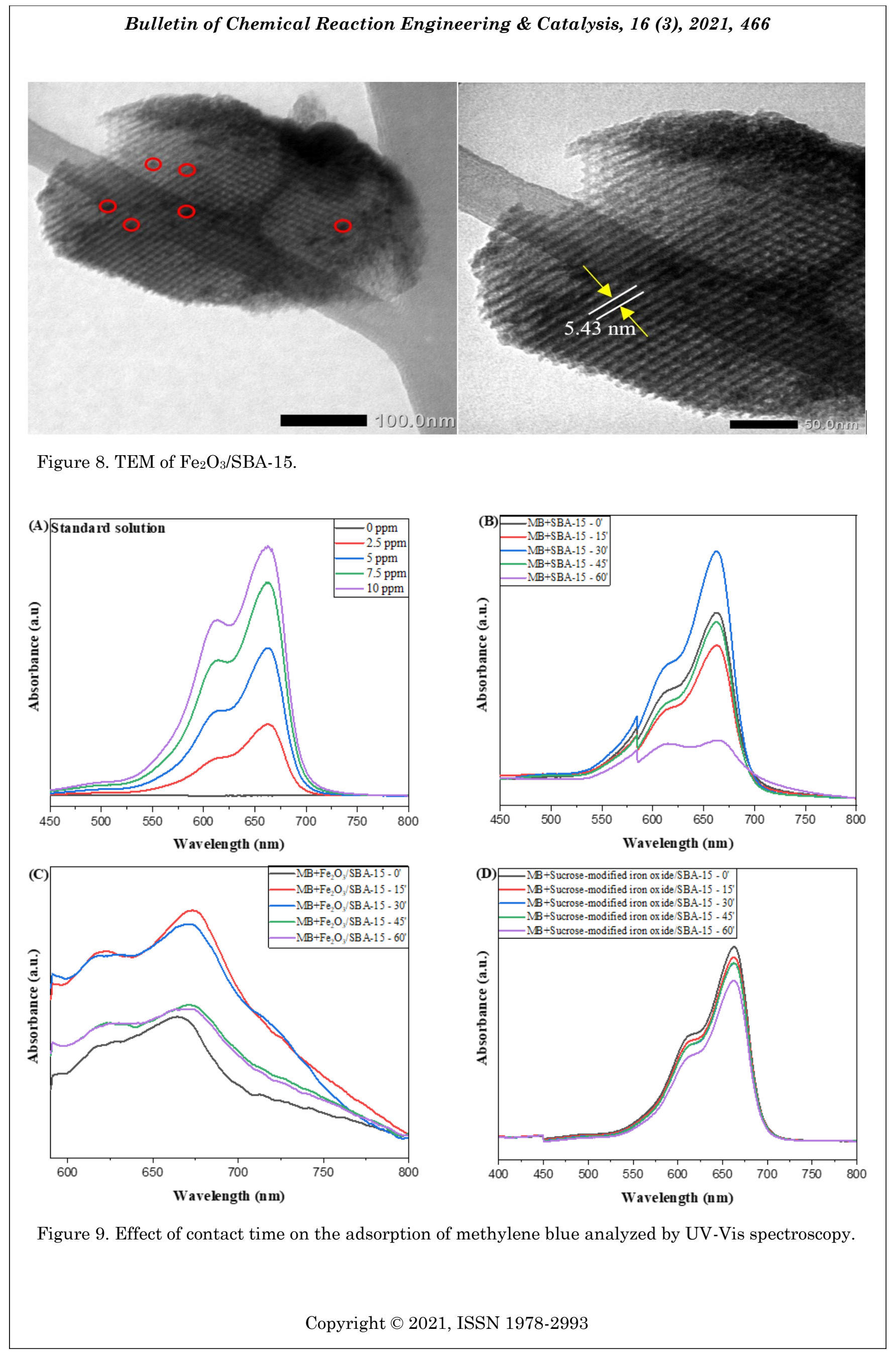


According to these observations, we could find the structural stability of silica mesopore SBA-15 after iron oxide was impregnated. After iron oxide-impregnation possessing peaks at 24.23 ; 32.25 ; $35.44 ; 39.31 ; 53.70$, and $62.77^{\circ}$ are attributed to the diffraction planes (110), (121), (110), (222), (132), and (130), respectively. These peaks are of iron species hematite phase or $\alpha-\mathrm{Fe}_{2} \mathrm{O}_{3}$ (JSPDC Card no. 85-0987).

After iron oxide impregnation, there was the iron oxide peaks are less visible, possibly due to the amorphous structure of silica material SBA-15, so that the peaks between SBA-15 and iron oxide overlap. The impregnation process of iron oxide on silica SBA-15 was successfully carried out and indicated by the color change in the material, where SBA-15 was a white powder after the impregnation process formed brick-red powder. In sucrose-modified SBA, Fe peaks are also seen even though the intensity decreases because some of the Fe is covered by carbon or other functional groups of sucrose.

The surface morphology of SBA-15, $\mathrm{Fe}_{2} \mathrm{O}_{3} / \mathrm{SBA}-15$, and sucrose-modified $\mathrm{Fe}_{2} \mathrm{O}_{3} / \mathrm{SBA}-15$ were explored by SEM analysis. As shown in Figure 7a, the morphology of pure SBA-15 showed a rod-like shape inconsistent with the one reported by Erdogan et al. [35]. SEM micrographs of both SBA-15 and $\mathrm{Fe}_{2} \mathrm{O}_{3} /$ SBA- 15 show a uniform and homogeneous surface as well as forming elongated arrays [36]. Sucrose-modified $\mathrm{Fe}_{2} \mathrm{O}_{3} / \mathrm{SBA}-15$ materials show the heterogeneous particle shape.

EDX measurement is used as quantitative analysis for the presence of the oxygen, silica, and metal components on the surface of the composites. The oxygen content slightly in-

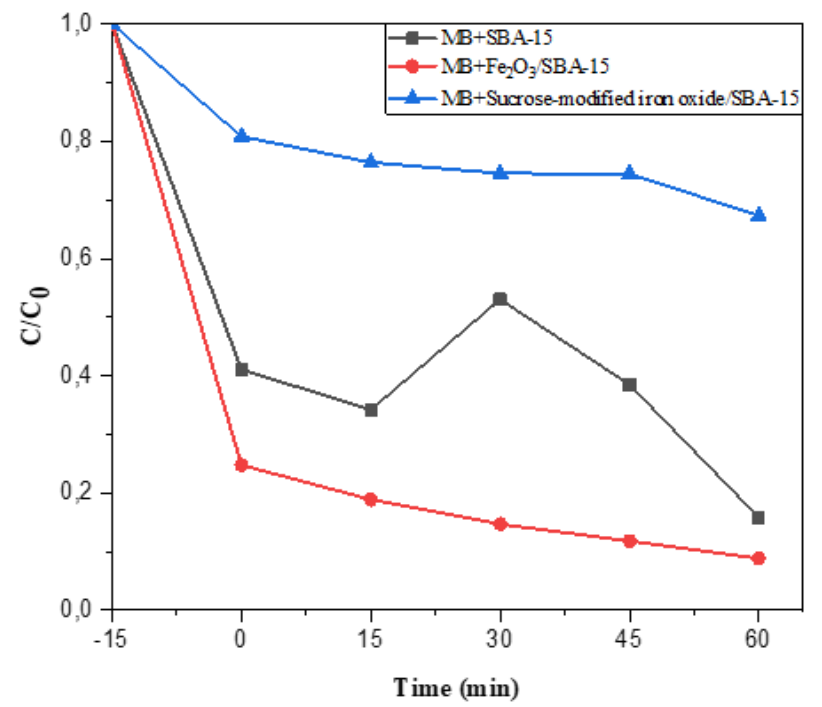

creases after impregnation and sucrosemodified (Figure 7b-c) due to the addition of iron oxide and sucrose. Elemental analysis of SBA-15 shows the presence of $\mathrm{Si} 53.5 \%$ and O $46.5 \%$, respectively. The impregnation of iron oxide was successfully carried out and it was shown in the EDX spectra that metal elements appeared 5.05\%. Sucrose-modified $\mathrm{Fe}_{2} \mathrm{O}_{3} / \mathrm{SBA}$ 15 was successfully and confirm from the elemental analysis showed that the presence of carbon $30.9 \%$ and metal elements appeared $2.2 \%$.

The structures of the iron oxide-containing materials were measured by transmission electron microscopy (Figure 8) shows the visualize the expected close-packed hexagonal arrangement of parallel mesopores characteristic of the p6 $\mathrm{mm}$ space group. The average wall thickness was $\sim 5.43 \mathrm{~nm}$ with similar width pore diameters [37]. The structure of $\mathrm{Fe}_{2} \mathrm{O}_{3} / \mathrm{SBA}-15$ consists of long-cylindrical pores running parallel to each other in the same direction and it is clear that the metal clusters are better dispersed.

The photocatalytic activity of SBA-15, $\mathrm{Fe}_{2} \mathrm{O}_{3} /$ SBA-15, and $\mathrm{Fe}_{2} \mathrm{O}_{3} /$ SBA-15 modified sucrose is shown in Figure 9 which shows a decrease in absorbance curve with increasing catalyst contact time with MB and has an efficiency percentage of $52.9,70.2$, and $21.1 \%$, respectively (Figure 10). The results are similar to previous studies which achieved an efficiency of $60-90 \%$ using pure iron oxide without the support material [38-40]. The iron oxide that has been successfully embedded in silica SBA15 has a hematite phase with a bandgap energy of $2.2 \mathrm{eV}$ [41]. However, catalytic activity

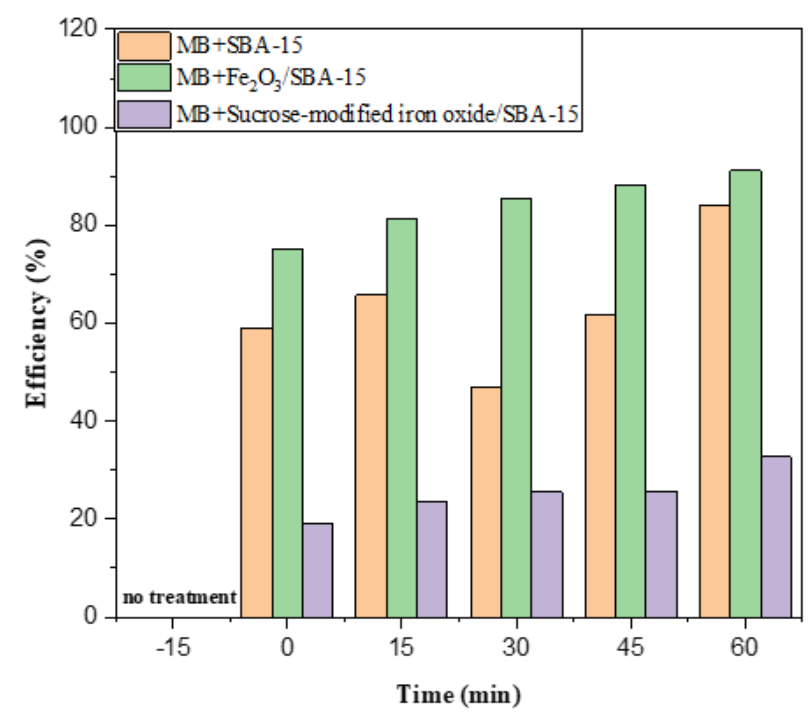

Figure 10. Photodegradation of $\mathrm{MB}$ using SBA-15, $\mathrm{Fe}_{2} \mathrm{O}_{3} / \mathrm{SBA}-15$, sucrose-modified $\mathrm{Fe}_{2} \mathrm{O}_{3} / \mathrm{SBA}-15$ (left) and efficiency percentage degradation of MB using catalyst (right). 
centered on $\mathrm{Fe}_{2} \mathrm{O}_{3} / \mathrm{SBA}-15$ utilizes the presence of iron oxide acts as a catalyst, and mesoporous SBA-15 with a large specific surface area can provide more active sites for the catalytic process and support the even dispersion of metal oxides $[6,42]$.

Degradation of MB with $\mathrm{Fe}_{2} \mathrm{O}_{3} / \mathrm{SBA}-15$ catalyst shows the best results compared to other materials, this is possible the role of iron oxide contained in silica SBA-15 to increase its photocatalytic activity. This is consistent with the use of hematite in other catalyst support materials, with $\mathrm{Zn}-\alpha-\mathrm{Fe}_{2} \mathrm{O}_{3}$ reaching an efficiency of up to $87 \%$ [43]. Bandgap reduction occurred in TiNPS- $\mathrm{Fe}_{2} \mathrm{O}_{3}$ and $\mathrm{AgNPs}-\mathrm{Fe}_{2} \mathrm{O}_{3}$ which increased photocatalytic activity in the degradation of Congo Red [44]. Degradation efficiency reaches $70 \%$ when using $\mathrm{Cu}-\mathrm{Fe}_{2} \mathrm{O}_{3}$ for the degradation of organic pollutants [45]. The result of the modification with sucrose on $\mathrm{Fe}_{2} \mathrm{O}_{3} / \mathrm{SBA}$ 15 has the lowest efficiency, which probably occurs due to the presence of pore-blocking and the formation of micropores on the external pore.

Another phenomenon observed in sucrosemodified $\mathrm{Fe}_{2} \mathrm{O}_{3} / \mathrm{SBA}-15$ samples is that high surface area has a weaker role than the catalytic center. It can be seen that the presence of carbon elements or other functional group residues from sucrose causes deactivation of the $\mathrm{Fe}$ element as a catalytic center capable of degrading methylene blue so it is very logical if the modification of $\mathrm{Fe}_{2} \mathrm{O}_{3} / \mathrm{SBA}-15$ with sucrose produces a lower MB photocatalytic performance than the unmodified. Besides, the interfacial interaction between iron oxide immobilized by the high surface area of the SBA-15 mesopore supports the adsorption which is important in the degradation process. Modification of sucrose in $\mathrm{Fe}_{2} \mathrm{O}_{3} / \mathrm{SBA}-15$ helps the catalyst in maintaining porosity in the SBA-15 mesopore [21].

\section{Conclusion}

Mesopore silica SBA-15 is an important substrate with attractive characteristics, such as adjustable pore size and possible functionalization using a variety of approaches. The surface functionalization method in this research has been successfully carried out by adding sucrose as a simple and low-cost organic molecule. The results of this study generally $\mathrm{Fe}_{2} \mathrm{O}_{3} / \mathrm{SBA}-15$ without modification and modification were successfully made. Unmodified samples showed higher catalytic performance than modified because of the presence of $\mathrm{Fe}$ as the catalytic center. Meanwhile, the modification process with sucrose has the advantage of producing a high surface area even though there is a catalytic center due to partial decomposition which causes a decrease in the efficiency of degradation of methylene blue. All materials provide a high micro surface area so that they can be further adapted and can be widely applied to many potential applications as both catalyst support and an adsorbent. Besides, variations in metal oxide precursors can be added in subsequent studies to determine the effect of using precursors on the iron oxide produced.

\section{Acknowledgements}

The author would like to thank the funding of the BPPTNBH Sebelas Maret University 2021 on scheme Program Penelitian Kolaborasi Indonesia (PPKI) in collaboration with Sepuluh Nopember Institute of Technology (ITS) and Gadjah Mada University (UGM) under project No. 102.1/UN27.22/HK.07.00/2021 for Maria Ulfa.

\section{References}

[1] Elahi, B., Mirzaee, M., Darroudi, M., Kazemi Oskuee, R., Sadri, K., Amiri, M.S. (2019). Preparation of cerium oxide nanoparticles in Salvia Macrosiphon Boiss seeds extract and investigation of their photo-catalytic activities. Ceramics International, 45, 4790-4797. DOI: $10.1016 /$ j.ceramint.2018.11.173

[2] Esfahani, M.R., Aktij, S.A., Dabaghian, Z., Firouzjaei, M.D., Rahimpour, A., Eke, J., Escobar, I.C., Abolhassani, M., Greenlee, L.F., Esfahani, A.R., Sadmani, A., Koutahzadeh, N. (2019). Nanocomposite membranes for water separation and purification: Fabrication, modification, and applications. Separation and Purification Technology, 213, 465-499. DOI: 10.1016/j.seppur.2018.12.050

[3] Antonopoulou, M., Evgenidou, E., Lambropoulou, D., Konstantinou, I. (2014). A review on advanced oxidation processes for the removal of taste and odor compounds from aqueous media. Water Res., 53, 215-234. DOI: 10.1016/j.watres.2014.01.028

[4] Tada, H., Kiyonaga, T., Naya, S. (2009). Rational design and applications of highly efficient reaction systems photocatalyzed by noble metal nanoparticle-loaded titanium(IV) dioxide. Chem Soc Rev., 38, 1849-1858. DOI: 10.1039/b822385h

[5] Tang, J., Wang, T., Sun, X., Guo, Y., Xue, H., Guo, H., Liu, M., Zhang, X., He, J. (2013). Effect of transition metal on catalytic graphitization of ordered mesoporous carbon and $\mathrm{Pt} / \mathrm{metal}$ oxide synergistic electrocatalytic 
performance. Microporous and Mesoporous Materials, 177, 105-112. DOI: 10.1016/j.micromeso.2013.04.027

[6] Ye, M., Tao, Y., Jin, F., Ling, H., Wu, C., Williams, P.T., Huang, J. (2018). Enhancing hydrogen production from the pyrolysisgasification of biomass by size-confined $\mathrm{Ni}$ catalysts on acidic MCM-41 supports. Catalysis Today, 307, 154-161. DOI: 10.1016/j.cattod.2017.05.077

[7] Bai, K., Hao, J., Yang, Y., Qian, A. (2020). The effect of hydrothermal temperature on the properties of SBA-15 materials. Heliyon, 6, e04436. DOI: 10.1016/j.heliyon.2020.e04436

[8] Kruk, M., Jaroniec, M., Ko, C.H., Ryoo, R. (2000). Characterization of the porous structure of SBA-15. J Chemistry of Materials, 12, 1961-1968. DOI: 10.1021/cm000164e

[9] Sanjini, N.S., Velmathi, S. (2014). Iron impregnated SBA-15, a mild and efficient catalyst for the catalytic hydride transfer reduction of aromatic nitro compounds. $R S C A d$ vances, 4, 15381-15388. DOI: $10.1039 / \mathrm{c} 3 \mathrm{ra} 46303 \mathrm{f}$

[10] Guillet-Nicolas, R., Marcoux, L., Kleitz, F. (2010). Insights into pore surface modification of mesoporous polymer-silica composites: introduction of reactive amines. New Journal of Chemistry. 34, 355-366. DOI: 10.1039/b9nj00478e

[11] Dong, X., Zhao, X., Wang, L., Zhang, M. (2016). One-step synthesis of hydrophobic fluorinated ordered mesoporous carbon materials. RSC Advances, 6, 48870-48874. DOI: 10.1039/c6ra06583j

[12] Kim, D., Zussblatt, N.P., Chung, H.T., Becwar, S.M., Zelenay, P., Chmelka, B.F. (2018). Highly Graphitic Mesoporous Fe,NDoped Carbon Materials for Oxygen Reduction Electrochemical Catalysts. ACS Appl Mater Interfaces, 10, 25337-25349. DOI: 10.1021/acsami.8b06009

[13] Naushad, M., Ahamad, T., Al-Maswari, B.M., Abdullah Alqadami, A., Alshehri, S.M. (2017). Nickel ferrite bearing nitrogen-doped mesoporous carbon as efficient adsorbent for the removal of highly toxic metal ion from aqueous medium. Chemical Engineering Journal, 330, 1351-1360. DOI: 10.1016/j.cej.2017.08.079

[14] Barczak, M., Michalak-Zwierz, K., Gdula, K., Tyszczuk-Rotko, K., Dobrowolski, R., Dąbrowski, A. (2015). Ordered mesoporous carbons as effective sorbents for removal of heavy metal ions. Microporous and Mesoporous Materials, 211, 162-173. DOI: 10.1016/j.micromeso.2015.03.010
[15] Banitalebi-Dehkordi, A., Shams, E., Farzin Nejad, N. (2018). Synthesis of iron oxide nanoparticles modified mesoporous carbon and investigation of its application for removing dibenzothiophene from fuel model. Environmental Nanotechnology, Monitoring \& Mana gement, $\quad 10, \quad 179-188$. D O I: 10.1016/j.enmm.2018.05.001

[16] Tyapkin, P.Y., Petrov, S.A., Chernyshev, A.P., Larichev, Y.V., Kirik, S.D., Gribov, P.A., Uvarov, N.F. (2017). Properties of iron oxides inserted into SBA-15 mesoporous silica. Materials Today: Proceedings, 4, 11392-11395. DOI: 10.1016/j.matpr.2017.09.015

[17] Baikousi, M., Georgiou, Y., Daikopoulos, C., Bourlinos, A.B., Filip, J., Zbořil, R., Deligiannakis, Y., Karakassides, M.A. (2015). Synthesis and characterization of robust zero valent iron/mesoporous carbon composites and their applications in arsenic removal. Carbon, 93, 636-547. DOI: 10.1016/j.carbon.2015.05.081

[18] Tran, M.H., Park, B.J., Kim, B.H., Yoon, H.H. (2020). Mesoporous silica template-derived nickel-cobalt bimetallic catalyst for urea oxidation and its application in a direct urea $/ \mathrm{H}_{2} \mathrm{O}_{2}$ fuel cell. International Journal of Hydrogen Energy, 45, 1784-1792. DOI: 10.1016/j.ijhydene.2019.11.073

[19] Barczak, M., Oszust-Cieniuch, M., Borowski, P., Fekner, Z., Zięba, E. (2011). SBA-15 silicas containing sucrose. Journal of Thermal Analysis and Calorimetry, 108, 1093-1099. DOI: $10.1007 / \mathrm{s} 10973-011-1973-\mathrm{z}$

[20] Li, H., Zhao, Y.S., Han, Z.T., Hong, M. (2015). Transport of sucrose-modified nanoscale zerovalent iron in saturated porous media: role of media size, injection rate and input concentration. Water Sci Technol, 72, 1463-1471. DOI: $10.2166 /$ wst.2015.308

[21] Janiszewska, E., Kowalak, S. (2017). Synthesis and catalytic performance in the propene epoxidation of a vanadium catalyst supported on mesoporous silica obtained with the aid of sucrose. New Journal of Chemistry, 41, 29551963. DOI: 10.1039/c6nj03632e

[22] Bharath, G., Anwer, S., Mangalaraja, R.V., Alhseinat, E., Banat, F., Ponpandian, N. (2018). Sunlight-Induced photochemical synthesis of $\mathrm{Au}$ nanodots on alpha$\mathrm{Fe}_{2} \mathrm{O}_{3} @$ Reduced graphene oxide nanocomposite and their enhanced heterogeneous catalytic properties. Sci Rep., 8, 5718. DOI: 10.1038/s41598-018-24066-y

[23] Zhao, D., Feng, J., Huo, Q., Melosh, N., Fredrickson, G.H., Chmelka, B.F., Stucky, G.D. (1998). Triblock copolymer syntheses of mesoporous silica with periodic 50 to 300 angstrom pores. Science, 279, 548-552. DOI: 10.1126/science.279.5350.548 
[24] Belmoujahid, Y., Bonne, M., Scudeller, Y., Schleich, D., Grohens, Y., Lebeau, B. (2015). SBA-15 mesoporous silica as a super insulating material. The European Physical Journal Special Topics, 224, 1775-1785. DOI: 10.1140/epjst/e2015-02498-3

[25] Thommes, M., Kaneko, K., Neimark, A.V., Olivier, J.P., Rodriguez-Reinoso, F., Rouquerol, J., Sing, K.S.W. (2015). Physisorption of gases, with special reference to the evaluation of surface area and pore size distribution (IUPAC Technical Report). Pure and Applied Chemistry, 87, 1051-1069. DOI: 10.1515/pac2014-1117

[26] Pudukudy, M., Yaakob, Z., Akmal, Z.S. (2015). Direct decomposition of methane over Pd promoted Ni/SBA-15 catalysts. Applied Surface Science, 353, 127-136. DOI: 10.1016/j.apsusc.2015.06.073

[27] Mahdavi, V., Mardani, M. (2015). Preparation of manganese oxide immobilized on SBA-15 by atomic layer deposition as an efficient and reusable catalyst for selective oxidation of benzyl alcohol in the liquid phase. Materials Chemistry and Physics, 155, 136-146. DOI: 10.1016/j.matchemphys.2015.02.011

[28] Deng, R., You, K., Yi, L., Zhao, F., Jian, J., Chen, Z., Liu, P., Ai, Q., Luo, H. (2018). Solvent-Free, Low-Temperature, Highly Efficient Catalytic Nitration of Toluene with $\mathrm{NO}_{2}$ Promoted by Molecular Oxygen over Immobilized $\mathrm{AlCl}_{3}-\mathrm{SiO}_{2}$. Industrial \& Engineering Chemistry Research, 57, 12993-13000. DOI: 10.1021/acs.iecr.8b02786

[29] Sun, Q., Hu, X., Zheng, S., Zhang, J., Sheng, J. (2019). Effect of calcination on structure and photocatalytic property of $\mathrm{N}-\mathrm{TiO} 2 / \mathrm{g}$ C3N4@diatomite hybrid photocatalyst for improving reduction of $\mathrm{Cr}()$. Environ Pollut., 245, 53-62. DOI: 10.1016/j.envpol.2018.10.121

[30] Sharma, G., Jeevanandam, P. (2013). Synthesis of self-assembled prismatic iron oxide nanoparticles by a novel thermal decomposition route. RSC Adv., 3, 189-200. DOI: $10.1039 / \mathrm{c} 2 \mathrm{ra} 22004 \mathrm{k}$

[31] Sardarian, A.R., Eslahi, H., Esmaeilpour, M. (2019). Green, cost-effective and efficient procedure for Heck and Sonogashira coupling reactions using palladium nanoparticles supported on functionalized $\mathrm{Fe}_{3} \mathrm{O}_{4} @ \mathrm{SiO}_{2}$ by polyvinyl alcohol as a highly active, durable and reusable catalyst. Applied Organometallic Chemistry, 33, e4856. DOI: 10.1002/aoc.4856

[32] Pan, X., Shi, Z., Shi, C., Hu, X., Wu, L. (2016). Interactions between inorganic surface treatment agents and matrix of Portland cementbased materials. Construction and Building Materials, 113, 721-731. DOI: 10.1016/j.conbuildmat.2016.03.091
[33] Fiorilli, S., Rivoira, L., Calì, G., Appendini, M., Bruzzoniti, M.C., Coïsson, M., Onida, B. (2017). Iron oxide inside SBA-15 modified with amino groups as reusable adsorbent for highly efficient removal of glyphosate from water. Applied Surface Science, 411, 457-465. DOI: 10.1016/j.apsusc.2017.03.206

[34] Ding, Y., Dan, H., Dong, X., Xian, Q., Wang, Y., Lu, X. (2017). A convenient solvothermal method to synthesize highly ordered mesoporous silica SBA-15 with high loading of amino groups. Materials Chemistry and Physics. $192, \quad 156-60, \quad$ D O I : 10.1016/j.matchemphys.2017.01.061

[35] Erdogan, B,. Arbag, H., Yasyerli, N. (2018). SBA-15 supported mesoporous Ni and Co catalysts with high coke resistance for dry reforming of methane. International Journal of Hydrogen Energy, 43, 1396-1405. DOI: 10.1016/j.ijhydene.2017.11.127

[36] Arroyo-Gómez, J.J., Toncón-Leal, C.F., dos Santos, A.J., Moreno, M.S., Sapag, K., Martínez-Huitle, C.A. (2020). Fe/SBA-15: Characterization and its application to a heterogeneous solar photo-Fenton process in order to decolorize and mineralize an azo dye. Materials Letters: $\quad X . \quad 5, \quad 100034$. DOI: 10.1016/j.mlblux.2019.100034

[37] Karthikeyan, S., Pachamuthu, M.P., Isaacs, M.A., Kumar, S., Lee, A.F., Sekaran, G. (2016). $\mathrm{Cu}$ and Fe oxides dispersed on SBA15: A Fenton type bimetallic catalyst for N,N -diethyl- $\mathrm{p}$-phenyl diamine degradation. Applied Catalysis B: Environmental, 199, 323330. DOI: 10.1016/j.apcatb.2016.06.040

[38] Bibi, I., Nazar, N., Ata, S., Sultan, M., Ali, A., Abbas, A., Jilani, K., Kamal, S., Sarim, F.M., Khan, M.I., Jalal, F., Iqbal, M. (2019). Green synthesis of iron oxide nanoparticles using pomegranate seeds extract and photocatalytic activity evaluation for the degradation of textile dye. Journal of Materials Research and Technology, 8, 6115-6124. DOI: 10.1016/j.jmrt.2019.10.006

[39] Ahmmad, B., Leonard, K., Shariful, I.Md., Kurawaki, J., Muruganandham, M., Ohkubo, T., Kuroda, Y. (2013). Green synthesis of mesoporous hematite $\left(\mathrm{a}-\mathrm{Fe}_{2} \mathrm{O}_{3}\right)$ nanoparticles and their photocatalytic activity. Advanced Powder Technology, 24, 160-167. DOI: 10.1016/j.apt.2012.04.005

[40] Sharma, J.K., Srivastava, P., Akhtar, M.S., Singh, G., Ameen, S. (2015). a- $\mathrm{Fe}_{2} \mathrm{O}_{3}$ hexagonal cones synthesized from the leaf extract of Azadirachta indica and its thermal catalytic activity. New Journal of Chemistry, 39, 71057111. DOI: 10.1039/c5nj01344e 
[41] Bassi, P.S., Gurudayal, G., Wong, L.H., Barber, J. (2014). Iron based photoanodes for solar fuel production. Physical Chemistry Chemical Physics, 16, 11834-11842. DOI: 10.1039/c3cp55174a

[42] Xiao, Y., Tian, G., Li, W., Xie, Y., Jiang, B., Tian, C., Zhao, D., Fu, H. (2019). Molecule Self-Assembly Synthesis of Porous Few-Layer Carbon Nitride for Highly Efficient Photoredox Catalysis. J. Am. Chem. Soc., 141, 25082515. DOI: $10.1021 /$ jacs.8b12428

[43] Suman, S., Chahal, S., Kumar, A., Kumar, P. (2020). $\mathrm{Zn}$ Doped $\mathrm{a}-\mathrm{Fe}_{2} \mathrm{O}_{3}$ : An Efficient Material for UV Driven Photocatalysis and Electrical Conductivity. Crystals, 10(4), 273. DOI: 10.3390/cryst10040273
[44] Muraro, P.C.L., Mortari, S.R., Vizzotto, B.S., Chuy, G., Dos Santos, C., Brum, L.F.W., da Silva, W.L. (2020). Iron oxide nanocatalyst with titanium and silver nanoparticles: Synthesis, characterization and photocatalytic activity on the degradation of Rhodamine B dye. Sci Rep., 10, 3055. DOI: 10.1038/s41598020-59987-0

[45] Twinkle, T., Singh, K., Bansal, S.A., Kumar, S. (2019). Graphene oxide (GO)/Copper doped Hematite $\left(\mathrm{a}-\mathrm{Fe}_{2} \mathrm{O}_{3}\right)$ nanoparticles for organic pollutants degradation applications at room temperature and neutral $\mathrm{pH}$. Materials Research Express, 6, 115026. DOI: 10.1088/2053-1591/ab4459 